\title{
A POPULARIZAÇÃO DAS TECNOLOGIAS DE INTELIGÊNCIA ARTIFICIAL BASEADAS EM MACHINE LEARNING E O SEU IMPACTO JURÍDICO-SOCIAL ${ }^{1}$
}

\author{
THE POPULARIZATION OF ARTIFICIAL INTELLIGENCE TECHNOLOGIES \\ BASED ON MACHINE LEARNING AND ITS LEGAL AND SOCIAL IMPACT
}

\author{
Angelita Woltmann² e João Vitor Corrêa Pacheco ${ }^{3}$
}

\section{RESUMO}

O presente trabalho pretende estudar as aplicações das recentes tecnologias de Inteligência Artificial (IA) notadamente aquelas baseadas em machine learning e suas consequências jurídicas. Se adotará uma metodologia qualitativa, amparada pelo método de procedimento monográfico e abordagem indutiva. A pesquisa é teórica, instrumentalizada pela técnica da pesquisa bibliográfica e embasada em fontes multidisciplinares desde teóricos das áreas sociais e tecnológicas, legislação, casos midiáticos publicizados na mídia digital.

Palavras-chave: Inteligência artificial. Direitos de personalidade. Novas tecnologias.

\begin{abstract}
The present work intends to study the applications of recent artificial intelligence (AI) technologies - notably those based on machine learning and its legal consequences. A qualitative methodology will be adopted, supported by the method of monographic procedure and inductive approach. The research is theoretical, instrumentalized by the technique of bibliographic research and based on multidisciplinary sources - from theorists in social and technological areas, legislation, media cases published in digital media.
\end{abstract}

Keywords: Artificial intelligence. Personality rights. new technologies.

\footnotetext{
1 Trabalho de Conclusão de Curso (TFG) de Direito da Universidade Franciscana (UFN) finalizado, submetido à banca avaliadora e aprovado no semestre 2020.2.

2 Orientadora da pesquisa. Doutora em Direito Público pela Universidade do Vale do Rio dos Sinos (UNISINOS). Mestre em Integração Latino-Americana pela Universidade Federal de Santa Maria (UFSM). Especialista em Direito Constitucional Aplicado pela Universidade Franciscana (UFN) e em Bioética pela Universidade Federal de Lavras (UFLA). Professora do Curso de Direito da UFN. Advogada (OAB/RS 61.713). E-mail: awoltmann@prof.ufn.edu.br e awoltmann@gmail.com 3 Autor da pesquisa. Bacharel em Direito pela Universidade Franciscana (UFN). E-mail :jvcpacheco98@gmail.com
} 


\section{INTRODUÇÃO}

Em uma sociedade conectada ciberneticamente, na qual os indivíduos estão constantemente "plugados" e dependem cada vez mais das novas tecnologias para automatizar suas tarefas - sejam elas funcionais ou meramente lúdicas - surgem diversos aplicativos e programas baseados em Inteligência Artificial (IA) ${ }^{4}$. Tais tecnologias servem-se aos mais diversos propósitos, desde a execução de atividades simples, auxiliando na gestão de objetivos diários - por exemplo, assistentes virtuais presentes nos smartphones e, cada vez mais, adquiridas para uso nas residências - até aquelas de natureza técnico-profissional - como aplicativos e plataformas virtuais que se prestam para edições de imagem, efeitos especiais e produção de conteúdo.

Tem-se, dentro de tal âmbito - delimitado como objeto de interesse desse trabalho científico aplicativos associados à tecnologia de machine learning ${ }^{5}$, isto é, baseiam- se nas entradas as quais os usuários inserem no programa e passam a realizar atividades de modo mecanizado, assim como aqueles nominados como tecnologias de deep learning ${ }^{6}$, os quais são programados de maneira a aprender progressivamente conforme são utilizados e vêm a se tornar mais precisos nas suas funções. Melhor esclarecendo, citam-se os programas que 'memorizam e determinam', com o passar do tempo, traços e expressões faciais do usuário na busca de uma edição aprimorada de imagem.

Ocorre que, diante da alta complexidade, variadas formas de utilização, rápidas atualizações e, principalmente, crescente e descontrolada disseminação fácil acessibilidade a todos os tipos de público, depara-se o Direito com um sem-número de casos controversos e ausência (ou mora) na regulação destes. Nesse sentido, o questionamento que se levanta no presente trabalho repousa em identificar quais os limites e possibilidades, no âmbito sociojurídico, quanto à utilização das tecnologias que possuem IA como componente essencial. Agregado a isto, pergunta-se, ainda: é possível determinar - no cenário nacional - qual é a situação jurídica das referidas 'inteligências'? E, finalmente: há adequado e suficiente enfrentamento pelo Direito dos conflitos relacionados a sua utilização no cotidiano? Ressalta-se que tais questões serão perseguidas meramente no aspecto teórico, deixando-se a pesquisa empírica para um momento futuro.

\footnotetext{
4 A partir desse momento, usar-se-á a sigla IA quando referir-se à Inteligência Artificial.

5 Traduzindo a expressão popularmente, pode-se dizer que significa "aprendizado automático". É conhecida por ser uma tecnologia comumente usada na área de Marketing Digital, notadamente, por profissionais especialistas em armazenamento de dados, garantindo, na maioria das vezes, aumento nas vendas em razão de publicidades direcionadas e alimentadas pelos próprios consumidores por meio de aplicativos sociais diversos.

60 presente artigo não adentrará nos aspectos técnicos (mecânica de funcionamento) que tal tecnologia envolve, visto que a área da pesquisa se limita à análise sociojurídica de sua utilização, traçando-se um panorama geral em relação aos limites e possibilidades, bem como riscos e consequências. Para aprofundamento em relação aos componentes técnicos, recomenda-se a leitura de autores que se dedicam ao tema, destacando-se Ian Goodfellow, Yoshua Bengio e Aaron Courville que, em 2016, publicaram, pelo MIT, um e-book concebido para auxiliar profissionais e estudantes de Ciência da Computação a aprofundarem-se na área. O livro está disponibilizado para download ou leitura online pelo site: http:// www.deeplearningbook.org/ (GOODFELOW, BENGIO e COURVILLE, 2016)
} 
A pesquisa justifica-se, socialmente, pelo exponencial crescimento do consumo de tecnologias de IA, cada vez mais acessíveis ao consumidor leigo (incluindo aí, crianças e adolescentes, caracterizados pela hipervulnerabilidade). No âmbito teórico, é relevante por fazer parte do nicho dos "novos direitos", adentrando em campos ainda incompreendidos pela Ciência Jurídica, visto que envolvem a complexidade intrínseca de temáticas típicas da cibercultura e que - embora já encontrem delineamento teórico especial na Academia, bem como, ótimos pesquisadores que se dedicam a observar, refletir e buscar respostas corretas para questões jurídicas frequentemente presentes em controvérsias envolvendo seu uso - ainda demandam esforço científico coletivo e financiamento estatal e privado para pesquisas que busquem aprofundar e preencher o vácuo normativo saliente na área, o que traz, necessariamente, insegurança jurídica aos consumidores que, não raro, acabam submetendo seus litígios ao Judiciário, em busca de "justiça". Demais disso, adapta-se à linha de pesquisa do Curso de Direito da Universidade Franciscana - "Teoria Jurídica, Cidadania e Globalização" - por se tratar de estudo teórico envolvendo temas ligados diretamente à sociedade em rede e respostas do Direito às questões sociais sobre novas tecnologias e direitos fundamentais.

Metodologicamente, utiliza-se a pesquisa qualitativa, amparada pelo método de procedimento monográfico e abordagem indutiva. Como instrumento para contruir os argumentos aptos a responder à problemática, utilizar-se-á a técnica da pesquisa bibliográfica e embasada em fontes multidisciplinares - desde teóricos das áreas sociais e tecnológicas, fontes normativas, documentos e jurisprudência, bem como, casos midiáticos publicizados em sites fundamentados por fontes conhecidas por sua confiabilidade.

A organização do trabalho se dá na seguinte forma: Na primeira seção se trará uma resumida visão acerca do que é a IA, assim como seu surgimento e aplicações práticas ao longo das décadas, assim como a maneira através da qual ela se manifesta no cenário moderno. Na segunda parte se questiona o estado jurídico das inteligências artificiais, assim como se busca elencar possíveis ameaças destas aos direitos dos membros de uma sociedade, pontuando-se, por oportuno, suas aplicações práticas no contexto jurídico brasileiro e internacional. Por fim, na seção três, por meio de alguns casos públicos famosos, pretende-se apontar os riscos e danos comprovados que a utilização das IA inadequadamente podem ocasionar aos direitos da personalidade, constitucionalmente protegidos no ordenamento jurídico brasileiro.

Como resultados finais da pesquisa ora proposta, importa descatar a impossibilidade de se deixar no trabalho, uma resposta fechada e que não se torne, em poucos anos, ultrapassada. No entanto, considerando a urgência no encontro de respostas adequadas aos problemas gerados pelo uso equivocado - intencional ou não - das tecnologias baseadas em Inteligência Artificial (IA), a pesquisa poderá servir como base para reflexão dos profissionais do futuro dos profissio-

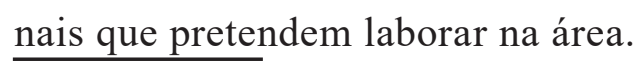

7 Compreendidos como produtos da nova cosmologia proposta pela revolução científica e (bio)tecnológica em curso, sendo necessária, ainda, sua abordagem e aprofundamento pelos estudiosos do Direito e de áreas correlatas. (OLIVEIRA JÚNIOR, 2000). 


\section{INTELIGÊNCIA ARTIFICIAL: "DO SONHO A REALIDADE"}

É impossível se trabalhar acerca de recentes tecnologias que surgem no horizonte sem antes explorar o conceito de inteligência coletiva, visto que a essência destes se unificam e se correlacionam como uma unidade, Pierre Lévy traz em sua obra "Cibercultura” a seguinte designação (LÉVY, 1999, p. 30):

Aquilo que identificamos, de forma grosseira, como "novas tecnologias" recobre na verdade a atividade multiforme de grupos humanos, um devir coletivo complexo que se cristaliza sobretudo em volta de objetos materiais, de programas de computador e de dispositivos de comunicação. É o processo social em toda sua opacidade, é a atividade dos outros, que retorna para o indivíduo sob a máscara estrangeira, inumana, da técnica. Quando os "impactos" são negativos, seria preciso na verdade incriminar a organização do trabalho ou as relações de dominação, ou ainda a indeslindável complexidade dos fenômenos sociais. Da mesma forma, quando os "impactos" são tidos como positivos, evidentemente a técnica não é a responsável pelo sucesso, mas sim aqueles que conceberam, executaram e usaram determinados instrumentos. Neste caso, a qualidade do processo de apropriação (ou seja, no fundo, a qualidade das relações humanas) em geral é mais importante do que as particularidades sistêmicas das ferramentas, supondo que os dois aspectos sejam separáveis. Resumindo, quanto mais rápida é a alteração técnica, mais nos parece vir do exterior. Além disso, o sentimento de estranheza cresce com a separação das atividades e a opacidade dos processos sociais.

A inteligência coletiva, por sua vez, corresponde-se diretamente -e em vias- com o virtual. De acordo com Pierre Lévy (1999, p. 47) "O virtual pode ser concebido em, pelo menos, três sentidos, o técnico, correlacionado à informática, um segundo, corrente e um terceiro, filosófico". Ademais, pontua que o fascínio atrelado a "realidade virtual" parte de uma confusão entre tais sentidos, visto que há um certo pensamento de que algo não pode ser simultaneamente real e virtual, e que portanto, a "realidade virtual" assume uma ressignificância 'mágica' para alguns, apesar de que sob uma perspectiva filosófica o real e o virtual não representam opostos, face que o virtual opor-se-á meramente ao atual.

Por fim, o autor sintetiza que a extensão do ciberespaço ${ }^{8}$ progride à uma célere virtualização geral da economia e da sociedade. Partindo para o campo mais técnico, um dos conceitos norteadores e básicos para a compreensão da questão da IA é, sem dúvida, o teste de Turing. Alan Turing, em 1950 idealizou um teste no qual um juiz humano entrevista outros humanos e computadores, por meio de um terminal, de modo que não saberá efetivamente quando está tratando com um computador ou com um ser humano propriamente dito. Caso o referido juiz não consiga desmascarar o computador, diz-se que o computador vence. Turing buscava demonstrar que o seu teste era um teste de pensamento, pois pensar implicaria uma intencionalidade consciente, e, portanto, a máquina seria dotada em certo grau, de uma inteligência. (KURZWEIL, 1999, p. 82)

\footnotetext{
8 A palavra "ciberespaço" foi inventada em 1984 por Wiliam Gibson em seu romance de ficção científica Neuromancer. No livro, esse termo designa o universo das redes digitais, descrito como campo de batalha entre as multinacionais, palco de conflitos mundiais, nova fronteira econômica e cultural (GIBSON, 1991).
} 
Foi em meados de 1980, no entanto, que efetivamente a IA começou a tomar formas mais promissoras, na época ela era um importante mecanismo utilizado em instituições financeiras ao redor do mundo, seja em mercados da bolsa de valores, títulos e moedas até na hora de decidir se deveria comprar ou vender ações. No mesmo período também surgiram tecnologias de eletrocardiograma automatizados e de bioengenharia. (KURZWEIL, 1999, p. 91). Sinteticamente, se pode afirmar que IA corresponde a arte de criar máquinas que executam funções que normalmente iriam requerer inteligência quando executadas por pessoas. (KURZWEIL, 1990 apud NORVIG E RUSSEL, 2004). Numa concepção mais moderna, afirma-se que para um sistema ser dotado de inteligência ele deverá ter habilidades consideradas de nível humano, como raciocínio, autonomia, planejamento, aprendizado, imaginação etc. (GABRIEL, 2018, p. 195).

Com os avanços obtidos em tecnologia e know how, vê-se a IA cada vez mais inserida no cotidiano do homem comum, engana-se quem pensa nela como uma criatura antropomórfica futurista, como se retrata em vários filmes, contudo, ela pode ser tão perigosa quanto. É possível percebê-la na própria palma da mão ao sacar o celular, já que praticamente todos os modelos de telefone do mercado vem equipados com assistentes virtuais, seja a Siri, da Apple ou a Google Assistant do Android. É enganoso pensar que isto seja algo inofensivo, afinal há um grande data mining ${ }^{9}$ ali, cada frase dita, comando ou pergunta feita é armazenada “em nuvem” e serve de substrato ao sistema. Evidentemente há métodos de proteção próprios das empresas responsáveis, entretanto, já é sabido que nada é absolutamente seguro, ou seja, podem ocorrer vazamento de dados sensíveis ${ }^{10}$. Outra tecnologia similar e quem vem ganhando boa parte do mercado nos últimos meses é a assistente virtual Alexa, da Amazon, que ouve 24 horas por dia o ambiente na qual é instalada, e novamente vale pensar acerca da real segurança dos dados ali computados. As tecnologias supracitadas se classificam como dotadas de machine learning, isto é, aprendem coisas de modo bastante limitado pela sua própria razão de ser e de existir.

\section{INTELIGÊNCIA ARTIFICIAL: DO "SER" À AMEAÇA DO "SER"}

Na presente seção do trabalho, busca-se trabalhar as inteligências artificiais à luz do Direito. Assim, procura-se trazer à lume questões controvertidas relacionadas ao atual status jurídico dessas tecnologias tão singulares. Nesse contexto, a pesquisa traça possíveis ameaças da má-utilização da IA aos direitos fundamentais, apontando-se algumas de suas aplicações práticas, com base na observação de casos no contexto jurídico nacional e internacional.

\footnotetext{
9 No contexto da obra entendido como o processo de obtenção e análise de dados pessoais dos usuários da rede, com a finalidade de estudar padrões, muitas vezes comportamentais e de personalidade.

10 Aqui entendidos como dados pessoais, em especial gostos e traços da personalidade.
} 


\section{O PAPEL DAS INTELIGÊNCIAS ARTIFICIAIS NO CAMPO JURÍDICO}

Há poucos anos, percebe-se a crescente utilização de sistemas mecanizados de julgamento, nos quais a figura do juiz é 'substituída' pela de um computador, baseado em machine learning, tecnologia anteriormente citada, que dentre diversas designações analisa o caso concreto e sugere decisões analisando precedentes jurídicos e a legislação vigente de determinado lugar. Como é o caso por exemplo do Tribunal de Justiça do Rio Grande do Norte, o qual estabeleceu parceria com a Universidade Federal local (UFRN) para desenvolver sistemas baseados em machine learning, uma delas, a denominada Clara, lê documentos, sugere tarefas e recomenda decisões, as quais devem ser avalizadas por um servidor posteriormente. É evidente que isto corrobora para um sistema judiciário mais ágil e simples, entretanto, sempre devemos lembrar que o país possui uma altíssima carga de processos, e é natural imaginar um cenário no qual eventualmente decisões impróprias sejam confirmadas por servidores, sem receberem adequada apreciação.

Por ser dotada de uma baixa arbitrariedade, o julgamento de sistemas assim é consideravelmente válido e assertivo em suas decisões, entretanto, isso não impediu o mecanismo de ser amplamente criticado e rechaçado pela mídia e por juristas ao redor do globo, vale citar o caso da utilização dela nos Estados Unidos para determinar o possível risco de cometimento de crime por indivíduos. O sistema em questão se baseia nos antecedentes criminais do indivíduo e prescreve uma sugestão a ser tomada pelo sistema baseado nisso, como por exemplo, qual o mecanismo de reintegração é o mais adequado, quanto tempo deve permanecer na cadeia antes do julgamento e inclusive o quão severa deve ser a penalidade.

Fica clara a problemática aqui, além de existir a falta do senso humano no julgamento, a vida do indivíduo se vê limitada e designada por eventuais delitos cometidos anteriormente, já que a operação básica de uma IA baseada em machine learning, conforme já explicou-se anteriormente, trabalha buscando padrões e realizando correlações, isto é, caso um sistema por exemplo determine que baixa renda é correlata com reincidência, pode vir a determinar, entre um universo de suspeitos, que o criminoso é aquele com tal característica.

Este sistema vem levantado inúmeros debates desde sua incorporação. Em julho de 2018, mais de cem organizações que versam sobre direitos civis, incluindo a $\mathrm{ACLU}^{11}$ e a $\mathrm{NAACP}^{12}$ realizaram um abaixo assinado, posicionando-se contra o sistema em questão.

Caso se imagine a tecnologia de deep learning adicionada a cifra, os riscos podem assumir proporções exacerbadas, face que, como já explicado, estas últimas possuem capacidade de desenvolver 'pensamentos' além do pré-estipulado por um desenvolvedor. Isto é, poderiam passar a criar precedentes, distorcer legislações e, eventualmente, até cometerem erros de julgamento. Se, por um 11 American Civil Liberties Union, ou, traduzido, União Americana pelas Liberdades Civis.

12 National Association for the Advancement of Colored People, ou, traduzido, Associação Nacional para o Progresso de Pessoas de Cor. 
lado, a utilização das tecnologias baseadas em IA auxiliam consideravelmente na eficácia e na transformação da ficção jurídica do princípio do prazo razoável em realidade, é plenamente possível que possam, eventualmente, ignorar especificidades naturais de casos complexos, culminando em decisões equivocadas, deixando um rastro de precedentes controversos. Para evidenciar tal questão, Raso (2018) aponta uma pesquisa realizada pela Universidade de Harvard (Berkman Klein Center) que sugere que, mesmo não intencionalmente, alogarítimos podem ser capazes de amplificar casos envolvendo discriminação e o racismo. Esse fator já é considerado em pesquisas acadêmicas da área jurídica, como demonstrado na pesquisa de Salvo (2020, p. 23-24), que aponta:

\footnotetext{
Mesmo que uma variável como raça seja retirada do algoritmo da sentença, o sistema ainda pode agrupar pessoas aparentemente aleatórias com base em outras categorias, como local de residência, que apontariam para os mesmos grupos minoritários. Essa mesma pesquisa mostrou que algoritmos de busca on-line estão reforçando a conexão entre nomes que soam como de indivíduos negros e atividades criminosas. Essa discriminação estatística indireta poderia ter os mesmos efeitos inconstitucionais que uma discriminação direta. Além disso, embora o uso dessa previsão possa reduzir a margem de discrição do juiz, ainda existe o perigo de que a discrição seja simplesmente transferida para promotores ou para aqueles que forneceriam dados de fato para o sistema.
}

Preocupada com essa mesma questão, Agra (2021), em estudo recente, trabalha os dois lados do uso da IA como ferramenta que visa melhorar a performance do Judiciário, recorrendo, para tanto, da análise do sistema COMPAS (Correctional Offender Management Profiling for Alternative Sanctions), utilizado nos Estados Unidos da América. Ela chama a atenção para o mesmo problema acima apontado, enfatizando que “[...] apesar dos significativos avanços observados após a implementação do software, fora percebido que o sistema apresentou análises tendenciosas e racistas que comprometeram o propósito inicial para o qual foi criado." (AGRA, 2021, p. 1).

Portanto, entende-se que esse é um paradoxo que, embora já suscitado em algumas publicações, ainda carece de estudos científicos interdisciplinares aprofundados. Se o humano é capaz de cometer erros, seria inocente pensar que uma tecnologia construída por humanos para executar suas tarefas de modo pensante escaparia à ausência de perfeição.

\section{A PERCEPÇÃO DA MÁQUINA COMO INDIVÍDUO}

Quando um desenvolvedor cria uma IA baseada em deep learning ele pode dotar a máquina com traços de personalidade humanos (GOODFELOW, BENGIO \& COURVILLE, 2016). Uma máquina "pensante" criada com tecnologia baseada em IA, por exemplo, pode se demonstrar como egoísta, amigável, cautelosa, etc.

Anteriormente, quando se referia àquelas baseadas em Machine Learning, o algoritmo se baseava em uma árvore de informações pré estipulada pelo desenvolvedor e ali restava-se, sendo via de 
regra, desprovida de traços humanos marcantes. A principal função de se dotar uma máquina com personalidade é a de permitir aos desenvolvedores terem uma maior compreensão e predileção quanto as possíveis decisões que àquela pode tomar, isto é, um algoritmo desenvolvido com a premissa de auxiliar investidores de uma instituição financeira poderá, baseada nos traços de personalidade inseridos, repreender determinada ação ou motivá-la.

Alguns algoritmos, por sua vez, são desenvolvidos de maneira a desenvolver sua personalidade e opiniões baseados nas interações com seres humanos, isto é, quando um conjunto de seres humanos lhe diz que algo é correto por certo tempo, a máquina tende a acatar aquilo como o certo e passar a replicar a informação, um exemplo polêmico quanto a isso foi a IA chamada Tay, desenvolvida pela Microsoft em 2016, destinada a interações através da plataforma de rede social Twitter. Tay havia sido concebida com a diretriz de simular uma garota média americana de 19 anos e aprender através da interação com outros seres humanos, entretanto, logo após seu lançamento pessoas má intencionadas começaram a sobrecarregar o Twitter utilizado para interação com mensagens de ódio e racismo, comportamento que a máquina imediatamente passou a tomar como correto e replicar, postando frases e memes racistas e de cunho sexual, sendo este o momento no qual a Microsoft desabilitou o recurso. Posteriormente ela foi reativada por engano e novamente persistiu no seu comportamento impróprio. Houve bastante apelo na internet, sobretudo em fóruns e plataformas afins, clamando pela reativação da Tay, alegando que a Microsoft estava censurando e calando a criação.

Existem diversas outras inteligências artificiais produzidas com o mesmo intuito, de aprender com o ser humano e desenvolver uma personalidade, algumas se mostraram de sucesso, como é o caso da 'Replika' um aplicativo popular para smartphones, concebido com a principal ideia de ajudar pessoas que sofrem de transtornos como depressão e ansiedade a se sentirem menos sozinhas, em que cada usuário cria sua IA e a mesma vai se tornando progressivamente mais humana e pensando de acordo com seu criador conforme o mesmo interage com ela através de mensagens, áudios e imagens, podendo-se inclusive realizar chamadas por voz com ela através do programa. É interessante aqui, em caráter prévio, trazer um entendimento acerca da senciência. Esta corresponde a capacidade de ser afetado de maneira positiva ou negativa, é a capacidade de sentir em si. Isto é diretamente correlacionado com a capacidade de ser consciente, isto é, capacidade de possuir determinados estados mentais, os quais variam dos mais rudimentares, como por exemplo, sentir dor, até aqueles mais complexos, como ser capaz de aprender ou pensar.

Assim como foi demorado para que os cientistas chegassem à conclusão sobre a sensciencia dos animais não-humanos, geralmente, concebidos juridicamente como "coisas"13, é relativamente

13 A senciência dos animais não-humanos é, cada vez mais, um fato aceito e não refutado, ética e juridicamente. Cientificamente, há, ainda escassez de pesquisas com rigor metodológico, embora, no campo dos animais vertebrados, se tenha informações válidas como argumento contra experimentos científicos com animais, por exemplo. Proctor, Carder e Cornish (2013) - por meio de revisão sistemática de literatura - descobriram que as vidas subjetivas dos animais não são apenas uma parte vital da pesquisa médica humana, mas sim, são regularmente, medidas e estudadas com rigor científico, validando a hipótese da senciência animal. 
complexo para os seres humanos determinar níveis de consciência externos e inerentes de "espécies" diferentes ${ }^{14}$. entretanto, é concebível, diante do previamente exposto nos parágrafos anteriores que máquinas tendem a se comunicar e trocar informações com o ambiente inserido, sendo que algumas inteligências inclusive são capazes de ser empáticas, como a já referida 'Replika'.

Logo, máquinas podem ser dotadas de traços humanos e de personalidade. Sob uma perspectiva jurídica, superficialmente ela é intrinsecamente ligada ao conceito de pessoa, o ordenamento refere que ao nascer com vida o indivíduo torna-se em uma pessoa, ou seja, adquire personalidade. Personalidade, portanto, é um conceito básico da ordem jurídica, é qualidade jurídica que se revela como condição preliminar de direitos e deveres. Além da pessoa natural também é concedida personalidade a determinadas entidades morais, as pessoas jurídicas. (GONÇALVES, 2012, p. 70).

Não se deve, no entanto, afirmar que pessoa natural se resume meramente a seres humanos biologicamente concebidos, visto que na modernidade existem tecnologias que propiciam a concepção da vida de maneira não natural. (FARIAS E ROSENVALD, 2018, p. 187). Sendo assim, superado o conceito de pessoa natural e adotando a premissa de que personalidade também é concedida à entidades morais sob forma de personalidade jurídica, esta comumente segregada da de seus membros, é assertiva a conclusão de que inteligências artificiais são passíveis de tornarem-se em seres dotados de personalidade, também em uma perspectiva jurídica. Acerca da personalidade jurídica Fábio Ulhoa (2012, p. 532) traz o seguinte:

Pessoa jurídica é o sujeito de direito personificado não humano. É também chamada de pessoa moral. Como sujeito de direito, tem aptidão para titularizar direitos e obrigações. Por ser personificada, está autorizada a praticar os atos em geral da vida civil - comprar, vender, tomar emprestado, dar em locação etc. --, independentemente de específicas autorizações da lei. Finalmente, como entidade não humana, está excluída da prática dos atos para os quais o atributo da humanidade é pressuposto, como casar, adotar, doar órgãos e outros.

Diante do exposto, entende-se que a pessoa jurídica possui aptidão à direitos e obrigações, restando-se necessário para tanto, um ato de vontade humana que constitua a mesma, sendo esta, após os adequados trâmites, inclusive dotada de autonomia jurídica, fator crucial para separar de modo claro os criadores da personalidade jurídica dela em si, Fábio Ulhoa (2012, p. 533) novamente elucida a importância da referida autonomia:

14 Repare bem: o autor aqui, considera, hipoteticamente, a possibilidade de máquinas dotadas de IA serem passíveis de, em algum momento futuro, adquirirem status jurídico de sujeitos de direito. A ideia parece retirada diretamente da literatura e cinema $s c i-f i$, mas, já é assunto debatido no cenário jurídico nacional e internacional. O Parlamento Europeu, no ano de 2017, apresentou uma normativa prevendo orientações sobre Robótica, incluindo aí proposta da criação de uma "personalidade eletrônica" para artefatos robóticos "inteligentes". Nesse sentido, um robô seria considerado inteligente e, consequentemente, apto para constituir registro próprio e formação de regimes de seguro e fundos de compensação, quando possuir as qualificações que seguem: a) existência de sensores capazes de permitir a troca de dados com o ambiente; b) capacidade de aprendizado com a experiência e interação com o meio; c) existência de um suporte material; d) capacidade de adaptação e e) ausência de vida na acepção biológica. Para além disso, a resolução sugestiona sobre a possibilidade de criação de um estatuto jurídico de robôs dotados de complexidade e IA, regulação que inovaria com a criação da personalidade jurídica eletrônica/robótica, fato que resultaria em direitos e deveres para máquinas (UNIÃO EUROPEIA, 2017). 


\begin{abstract}
A mais relevante consequência dessa conceituação das pessoas jurídicas é sintetizada no princípio da autonomia. As pessoas jurídicas não se confundem com as pessoas que a integram - dizia preceito do antigo Código Civil. Em outros termos, a pessoa jurídica e cada um dos seus membros são sujeitos de direito autônomos, distintos, inconfundíveis. (...) Em razão do princípio da autonomia da pessoa jurídica, é ela mesma parte dos negócios jurídicos. Faz-se presente à celebração do ato, evidentemente, por meio de uma pessoa física que por ela assina o instrumento. Mas é a pessoa jurídica que está manifestando a vontade, vinculando-se ao contrato, assumindo direitos e contraindo obrigações em virtude do negócio jurídico.
\end{abstract}

Ora, o desenvolvimento de uma IA, naturalmente, é caracterizado por conter elementos ligados à autonomia de vontade, tal como a qualidade mais ligada às liberdades dos indivíduos humanos para realizar atos jurídicos. Assim: "A discussão sobre os fundamentos ontológicos que separam pessoas e robôs tem se mostrado insuficiente para afastar a defesa da personalidade jurídica dos artefatos robóticos com inteligência artificial.” (NEGRI, 2020, p. 11). Nesse sentido:

A personalidade eletrônica é apresentada como uma resposta aos problemas da responsabilidade civil tendo em vista possíveis danos que possam ser causados pelos artefatos robóticos. Com efeito, nota-se uma confusão nessa forma de abordagem: a atribuição de uma suposta personalidade jurídica para robôs é tratada como se fosse uma decorrência automática do debate sobre a responsabilidade. (NEGRI, 2020, p. 3).

Pagallo (2018) atenta para uma importante questão inerente ao Direito. Para compreender - seja defendendo ou criticando - a ideia de adoção da personalidade jurídica eletrônica (para robôs dotados de IA), é preciso passar pelo histórico da conquista da personalidade jurídica por entidades como autarquias, sociedades empresárias, associações e fundações, necessariamente. Se o Direito teve que se adequar à presença de pessoas jurídicas nas relações sociais, transcendendo a compreensão do conceito de personalidade jurídica (antes, restrita ao ser humano, como pessoa física individual somente), por qual motivo é impossível conceber que um "ser” (máquina) criado artificialmente pelo homem e dotado de quase todos os elementos antropomorficos que o caracterizam $^{15}$ ?

\title{
BUSCANDO MINIMIZAR O CONFLITO ENTRE O EMPREGO DE INTELIGÊNCIAS ARTIFICIAIS E A PRESERVAÇÃO DOS DIREITOS DA PERSONALIDADE
}

Esta seção tem o condão de conceituar brevemente o que é deep learning e machine learning, aborda-se também brevemente alguns conceitos relevantes acerca do direito de personalidade interessantes ao escopo do presente trabalho, tal como a ameaça que as novas tecnologias oferecem a estes.

15 Metaforicamente, a vida imita a criação bíblica cristã do mundo e do humano por um "deus", em Gênesis. 


\section{MACHINE LEARNING E DEEP LEARNING: COMPREENDENDO CONCEITOS}

O machine learning corresponde a um campo da IA que faz com que o próprio sistema aprenda, baseado num código pré inserido, através de experimentações e busca de padrões, existem diversos algoritmos de tal processo, os de redes neurais, os de aprendizagem por reforço, genéticos, dentre outros. (GABRIEL, 2018, p. 197). O data mining, conceito fundamental para compreensão do tema, por sua vez, é um subcampo da ciência computacional que sobrepõe quantidades massivas de dados no objetivo de obter padrões, estatísticas, dentre outros dados. Graças as recentes explosões de dados oriundas de vazamentos de big data ${ }^{16}$, esse campo se torna de grande valia no processo de alimentar sistemas com dados, e consequentemente, torná-los inteligentes (GABRIEL, 2018, p. 208).

Apesar de terem sido revolucionárias em seu tempo, os sistemas baseados em machine learning se demonstraram bastante obsoletos quando aplicados na prática, pois havia uma constante necessidade destas de serem 'alimentadas' com dados por desenvolvedores, logo, urgiu-se por novas perspectivas e métodos de aprendizado, o que veio a dar origem ao processo de deep learning. Graças a recentes evoluções nos campos de hardware tornou-se possível emular redes neurais ${ }^{17}$ de maneira mais complexa e próximas as existentes na mente do ser humano, o deep learning utiliza algoritmos de redes neurais artificiais de modo que consiga formar redes de neurônios para resolver problemas mais complexos, chegando mais próxima da maneira como entendemos o conceito de 'pensar' (GABRIEL, 2018, p. 211).

Outro fator que corrobora, e muito, para a crescente popularização da metodologia do deep learning vem a ser a já citada onda de propagação de dados em meios virtuais, aprimoramento de dispositivos de reconhecimento de fala, dentre outros. Tudo isso acaba por vir a servir de substrato para tais tecnologias. A soma do hardware, software e disponibilidade de dados vem a criar o que se entende como computadores neuromórficos, isto é, máquinas capazes de pensar de modo praticamente autônomo, sem necessitar da constante de um desenvolvedor inserindo- lhe dados e padrões (GABRIEL, 2018, p. 213).

\footnotetext{
16 Sinteticamente entendido como um grande volume de dados, o qual pode ser de âmbito social, empresarial ou pessoal. No contexto deste trabalho, refere-se a dados demográficos e comportamentais de grupos sociais. Destaca-se, aliás, que não são incomuns notícias acerca do vazamento destes dados.

17 A primeira concepção sobre redes neurais foi construída pela dupla de cientistas Warren McCulloch e Walter Pitts no ano de 1943 e considerada, até hoje, um "divisor de águas" nos estudos sobre o tema. Os pesquisadores explicaram, na publicação, como os neurônios deveriam funcionar e, partindo disso, criaram o primeiro modelo de uma rede neural simples, com circuitos elétricos. (McCULLOCH \& PITTS, 1943). Essa descoberta foi considerada o ponto de partida para a aplicação do conceito em duas áreas, predominantemente: a primeira, ligada aos processos biológicos no cérebro e a outra, com aplicabilidade direta no campo da tecnologia de IA. Foi Kunihiko Fukushima, em 1975, que desenvolveu a primeira rede neural multicamada. Sua proposta original pautava-se em possibilitar a criação de uma rede neural para uso via sistema computacional, inovando no campo tecnológico com objetivo de resolver problemas, tal como um "cérebro humano" (FUKUSHIMA, 1975). Dada a largada para o uso prático das redes neurais, pesquisadores adaptaram a ideia focando na resolução artificial de tarefas específicas. Atualmente, utilizam-se redes neurais para inumeráveis ações ligadas à tecnologias, especialmente em estratégias de jogos de tabuleiro e games. Além disso, a serventia das redes neurais estende-se à inclusão tecnológica, a exemplo do uso para visão computacional, reconhecimento de fala, tradução de máquina, filtragem de redes sociais e até diagnósticos médicos.
} 
O deep learning ainda é de certa forma bastante recente e vê-se brevemente explorado, porém é aqui, como dito acima, que as máquinas começam a ser percebidas com a capacidade de ser, isto é, se tornar em mecanismos pensantes. Observamos sua existência em diversos programas que trabalham com processamento de imagem e 'chatbots' (bate-papos com IA's) modernos. Elas conseguem, por exemplo, determinar quais elementos devem ser alterados em certa imagem, ou o que dizer para uma pessoa em determinado momento. Evidentemente resta-se notar que sua utilização ainda é bastante banal e para finalidades triviais, contudo, a história evolutiva das IAs nos mostram que é assim que seu uso começa.

O deep learning pode ser designado como um subcampo da machine learning, funcionando, contudo, de uma maneira mais autônoma e inteligente em relação aos demais métodos do macro grupo. Em termos gerais é um marco evolutivo, que tende a se perpetuar como padrão em um futuro próximo.

\section{OS DIREITOS DA PERSONALIDADE: UMA BREVE ANÁLISE SOB ESCOPO DO CÓDIGO CIVIL E DOUTRINA}

Pode-se tomar a personalidade como um dos mais preciosos bens jurídicos, visto que é em razão do reconhecimento desta que advém o respeito à preceitos básicos para uma vida digna, tais como a conservação da honra. Nesse sentido, Szaniwaski (2002, p. 35) traz a seguinte elucidação:

\footnotetext{
Personalidade se resume no conjunto de caracteres do próprio indivíduo; consiste na parte intrínseca da pessoa humana. Trata-se de um bem, no sentido jurídico, sendo o primeiro bem pertencente à pessoa, sua primeira utilidade. Através da personalidade, a pessoa poderá adquirir e defender os demais bens (...). Os bens que aqui nos interessam são aqueles inerentes à pessoa humana, a saber: a vida, a liberdade e a honra, entre outros. A proteção que se dá a esses bens primeiros do indivíduo denomina-se direitos da personalidade.
}

Visto que os direitos da personalidade são extremamente complexos por sua natureza, o legislador não criou uma definição expressa na redação normativa, encargo este que restou para os doutrinadores e juristas. Em caráter genérico e sucinto, vêm o entendimento de Paiva Neto, que define que o mesmo compreende totalmente as necessárias condições para que se conserve e desenvolva a personalidade, e para que exista o reconhecimento e respeito da dignidade jurídica e moral do homem (PAIVA NETO apud SZAWINASKY, 2000, p. 37). Rodrigues, por sua vez, traz que os direitos de personalidade são aqueles, que em virtude de ser ligados de maneira perpétua e permanente, são inerentes à pessoa, inconcebível sendo um indivíduo que não tenha direito a vida, liberdade física, intelectual ou ao seu nome, imagem e àquilo em que crê ser passível de sua honra (RODRIGUES, 1994, p. 81)

Os direitos da personalidade possuem diversas características atribuídas a si em razão de sua peculiaridade e objeto de tutela. No artigo 11 do Código Civil brasileiro, o legislador prevê o seguinte: “Com exceção dos casos previstos em lei, os direitos da personalidade são intransmissíveis e 
irrenunciáveis, não podendo seu exercício sofrer limitações”. (BRASIL, 2002). Via de regra, o direito referido não se limita através de ato voluntário de seu possuidor, e, também, não pode ser meramente renunciado ou transmitido a outrem, em virtude de encontrar respaldo na proteção do indivíduo em si. Evidentemente, admite-se, em determinadas hipóteses, a limitação voluntária e temporária do exercício de alguns direitos de personalidade, quando essas forem permitidas ou não contrariarem a ordem jurídica e os "bons costumes” (GUHUR, 2003. p. 135-136).

Relevante é, também, a característica de imprescritibilidade dos direitos da personalidade. Eles acompanham seu titular além da vida. Ou seja, até mesmo após a morte pode existir, seja na proteção de determinada obra, tutela do nome, honra, etc. Logo, os parentes podem resguardar os direitos da personalidade do de cujus, conforme explicitado no Art. 12 do Código Civil brasileiro, uma vez que estes são considerados direitos 'perenes'. É de suma importância apontar também que os direitos da personalidade são absolutos, isto é dizer que, opõe-se de maneira erga omnes, ou seja, podem ser opostos contra todos de maneira indeterminada, inclusive contra o Estado ou pessoas jurídicas, não dependendo de uma prévia relação entre as partes, sendo suficiente a mera lesão ao direito (SOUZA, 2002, p. 12).

\section{TECNOLOGIA, INTELIGÊNCIA ARTIFICIAL E DIREITO: A AMEAÇA NA PRÁTICA}

Já demonstrada a hipótese das inteligências artificiais como entidades passíveis de personalidade sob a hipótese social e jurídica, assim como abordados alguns conceitos acerca dos direitos da personalidade, é oportuno apontar os riscos e danos comprovados que ela oferece aos direitos da personalidade resguardada em nosso ordenamento ${ }^{18}$.

Em virtude de avanços científicos na área exaustivamente trabalhados nos tópicos anteriores, é notório pontuar que a personalidade passa a sofrer novas ameaças, que devem ser enfrentadas com regulamentação da sua proteção, visto que o direito da personalidade em si, e consequentemente o de imagem, vai além das hipóteses catalogadas na norma fundamental e na legislação ordinária (GONÇALVES, 2012, p. 139). Um exemplo dos riscos da IA aos direitos da personalidade que foi amplamente noticiado na mídia foi o da substituição do rosto de uma atriz da indústria pornográfica pela famosa Gal Gadot, Assim como diversos outros vídeos produzidos de maneira satírica, como por exemplo, colocar políticos famosos em situações engraçadas, como foi o caso ocorrido em meados deste ano, no qual um humorista colocou o presidente da república, Jair Bolsonaro, através de tecnologias de deepface, a cantar a música “pintinho piu”. (COUTINHO, 2019).

Os programas baseados em deep learning exigem um hardware de ponta para serem adequadamente manejados, isto é, dificilmente alguém com um computador doméstico convencional ou até

18 Não se pretende aprofundar sobre as consequências da hipotética adoção responsabilidade jurídica das IA em relação às vertentes de sua personificação, seja atuando como vítima ou como ofensora em um litígio. 
mesmo voltado a programação, com poderosas placas de processamento de vídeo conseguiria executar tais programas de modo adequado, entretanto, o mecanismo que as empresas desenvolvedoras vêm utilizando nos últimos tempos é o de processar os vídeos ou imagens de maneira remota, em servidores extremamente potentes, possibilitando então que a tecnologia seja de uso simples e acessível a qualquer um possuidor de um smartphone.

Isso é bastante visto em algumas aplicações práticas. A título de exemplo, pode-se citar o Ray Tracing, tecnologia que busca criar reflexos e sombreados hiper realísticos em tempo real em vídeos e jogos, utilizando-se para tanto da IA como sua principal ferramenta de funcionamento, tornando então eventuais produções baseadas em IA ainda mais convincentes. Outro exemplo é o popular 'facelab', desenvolvido em meados de 2017 o aplicativo trouxe a proposta de modificar o rosto do usuário, seja para envelhecê-lo, mudar o estilo e a cor do cabelo, alterar expressões faciais, dentre outros fins. Outro aplicativo que ganhou grande notoriedade no presente ano foi o aplicativo de iOS 'impressions app' o qual surpreende pela maneira extremamente realística através da qual insere o rosto de uma celebridade numa pessoa em vídeo rapidamente, fazendo em segundos o que outrora iria requerer além de uma máquina potente, horas de edição de imagem e conhecimento de programação.

$\mathrm{Na}$ figura abaixo, observa-se as capacidades do aplicativo Impressions, à esquerda o usuário e à direita sua transformação no ator Jim Carrey através do algoritmo de deep learning utilizado.

Figura 1 - App Impressions

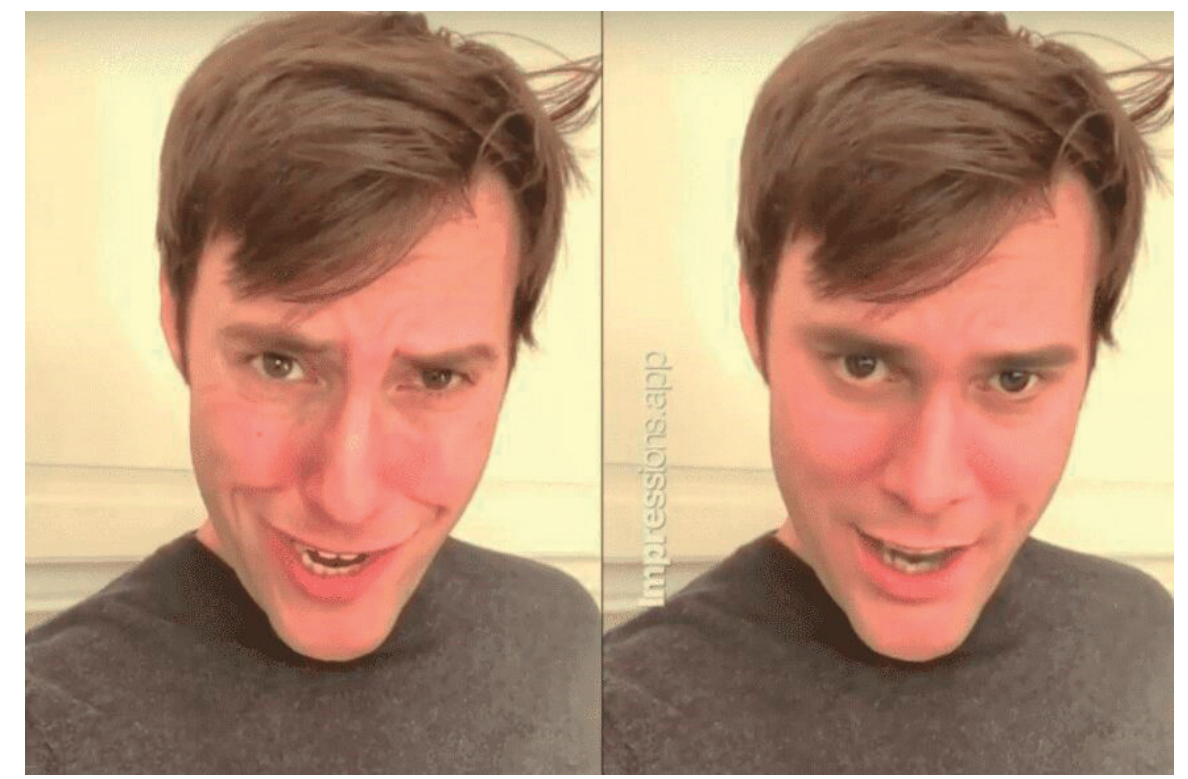

Fonte: UPDATE OR DIE. Disponível em: https://bit.ly/3eP132u Acesso em: 2 nov.2020.

O risco de tais tecnologias é imenso, caso um usuário resolva utilizar-se destas mal intencionado, poderia eventualmente macular a reputação de determinada pessoa, ou até mesmo, numa hipótese altamente improvável porém não impossível, fazer um político ou figura pública realizar declarações controversas que poderiam gerar tensões entre países e inclusive culminar em conflitos. 
Um dos meios utilizados pelas desenvolvedoras para coibir tal finalidade é o de inserir marcas d'água nas produções, ou ainda deixar eventuais traços de que o vídeo ou imagem fora manipulado no código fonte da obra, entretanto, muitos aplicativos possuem a opção de desabilitar a logomarca ao pagar, e inclusive os eventuais traços comprobatórios de manipulação no código do vídeo também tendem a se perder nas diversas conversões e compartilhamentos das produções nas redes sociais e afins.

Outra questão alarmante é quanto aos dados processados em programas de tal estirpe, visto que os usuários necessitam de realizar o 'upload' de suas fotos e vídeos aos servidores remotos dos programas. Isso acaba por gerar uma quantidade imensurável de clusters de dados, componentes dos já citados anteriormente "big datas", os quais além de ameaçar seriamente a imagem dos usuários comuns em eventuais invasões de sistema, acabam alimentando estes algoritmos e tornando-os cada vez mais precisos e incisivos em suas capacidades. Ademais, vale-se pontuar também que nos dias atuais, onde a conexão e as redes sociais integram o cotidiano, a maior parte das pessoas possuem inúmeras fotos e vídeos públicos espalhados pela internet, seja em contas de Instagram ou Facebook ou até mesmo em amontoados de dados de caches de site compilados pelo Google e adicionados a imensurável, e de fácil acesso, biblioteca de imagens do buscador.

\section{CONSIDERAÇÕES FINAIS}

“- Mas... nós controlamos essas máquinas, elas não nos controlam? - Claro que não, como poderiam?

A ideia pode ser idiota, mas... faz pensar... O que é controle?

- Quando quisermos podemos desligar essas máquinas.

- É claro.... É isso, você acertou. Isso é controle, não é? Se quiséssemos poderíamos destruir tudo. Mas se fizéssemos deveríamos pensar o que iria acontecer com nossas luzes, nosso aquecimento, nosso ar. - Então, nós precisamos das máquinas e elas de nós. Esse é o seu ponto de vista Conselheiro? - Não, não é. Eu não me preocupo em criar um ponto de vista."

(Diálogo entre Neo e o Conselheiro, no filme “Matrix Reloaded", 2003)

A metáfora da trilogia de Matrix ilustra, sob o panorama artístico, um mundo em que as máquinas assumem o controle. Talvez, a película cinematográfica tivesse, realmente, a intenção de provocar o sentimento de "medo" em relação ao futuro. A proposta de universos paralelos dominados pelo fracasso do humano como "ser" dominante, lutando contra o controle de suas próprias criações, que, não intencionalmente, acabam por superá-lo.

As tecnologias baseadas em IA são criadas para serem "pensantes" - mesmo com comportamentos nivelados diferentemente do padrão humano - já são capazes de fazer muitas tarefas consideradas, em tempos remotos, como exclusivas do domínio humano (a exemplo da matemática e da memória) de modo a superá-lo. Diante do exposto, é notório que a sociedade, a passos largos e rápidos, 
se vê rumando para um futuro baseado na aplicação, cada vez mais cotidiana, das tecnologias de IA e estas, por sua vez, evoluem de modo exponencial.

A ideia da pesquisa aqui apresentada surgiu em 2019 e, apenas no curso do período de traba1ho, se observou diversas novas tecnologias associadas ao deep learning e às IA surgirem no horizonte. Considerando, ainda, o fato de que na sociedade moderna, cada vez mais, carece de soluções e resultados ágeis, é imprescindível a discussão e aprofundamento do Direito acerca do tema, visto que, na ignorância disso, a sociedade facilmente se afogaria nas próprias criações.

Convém, brevemente, rememorar a ideia de Pierre Lévy acerca dos impactos da cibercultura, exposta no trecho que iniciou a primeira seção deste trabalho. De maneira resumida, o filósofo estipula que todo ônus e bônus obtido através de uma tecnologia não é mérito desta, mas, sim, da sociedade na qual ela se vê inserida (por exemplo, a criação e utilização de bombas nucleares não é culpa da tecnologia da fissão atômica, mas do homem que lhe atribuiu tal diretiva). Quando adiciona-se IA nesta equação, ela se torna complexa, visto que é a partir desse momento, em que se percebe que as máquinas com sua a capacidade de "ser", tornando, então, confuso e nebuloso o horizonte baseado em velhas concepções acerca da tecnologia. Necessária é a compreensão clara disso na resolução de possíveis conflitos jurídicos originados do uso deturpado dessa tecnologia tão atrativa e tão perigosa simultaneamente.

É evidente que - pela natureza complexa do tema - é muito provável que no porvir, as conclusões deste trabalho se tornem obsoletas, frente a veloz evolução da tecnologia e das controvérsias consequentes de sua utilização. Contudo, o objetivo principal desta pesquisa acadêmica foi cumprido: acenar para a urgência da presença do Direito em um cenário no qual a aplicação mais mundana das tecnologias de IA podem gerar efeitos paradoxais devido aos complexos riscos envolvidos.

\section{REFERÊNCIAS}

AGRA, Júlia Monteiro Lucena. Inteligência artificial e a dosimetria da pena: robôs racistas? In: Juristas. Publicado em 28 jan. 2021. Disponível em: https://bit.ly/3FPUbxT. Acesso em: 30 nov. 2021.

ALLEN, C.; BEKOFF, M. Species of mind: The philosophy and biology of cognitive ethology. Cambridge: MIT Press, 1997.

BRASIL. Projeto de Lei da Câmara n 27, de 2018. Acrescenta dispositivo à Lei $n^{\circ} 9.605$, de 12 de fevereiro de 1998, para dispor sobre a natureza jurídica dos animais não humanos. Disponível em: https://bit.ly/3zsPAiB. Acesso em: 11 dez. 2019.

COELHO, Fábio Ulhoa. Curso de Direito Civil. Parte Geral. 5. ed. Volume 1. São Paulo: Saraiva, 2012. 
COUTINHO, Dimitria. O que é Deepfake? Saiba como funciona e porque tecnologia pode afetar a política. Tecnologia.ig, 2019. Disponível: https://bit.ly/3mSX4Xq. Acesso em: $11 \mathrm{dez} .2019$.

ÉTICA ANIMAL. O que é senciência. Disponível em: https://www.animal-ethics.org/senciencia-secao/senciencia-animal/. Acesso em: 11 dez. 2019.

FARIAS, Cristiano Chaves de; ROSENVALD, Nelson: Curso de direito civil: parte geral e LINDB. 16. ed. Salvador: JusPodivim, 2018.

FUKUSHIMA, Kunihiko. Cognitron: A self-organizing multilayered neural network. Biol. Cybernetics 20, 121-136 (1975). Disponível em: https://doi.org/10.1007/BF00342633 Acesso em: 30 nov. 2021.

GABRIEL, Martha. Você, eu e os robôs: Um pequeno manual do mundo digital. São Paulo: Atlas, 2018.

GIBSON, William. Neuromancer. São Paulo: Editora Aleph, 1991.

GONÇALVES, Carlos Roberto. Direito civil brasileiro: parte geral. Volume 1. 10 . ed., São Paulo: Saraiva, 2012.

GOODFELOW, Ian; Yoshua, BENGIO; Aaron, COURVILLE. Deep learning. MIT Press: Massachusetts, 2016. Disponível em: http://www.deeplearningbook.org. Acesso em: 09 nov. 2019.

GUHUR, Jaqueline Sophie Perioto. Programas de televisão e pessoas com necessidades especiais: uma reflexão acerca do grotesco e da tutela civil da dignidade humana. Maringá, 2003. 195 f. Dissertação (Mestrado em Direito), Universidade Estadual de Maringá, Maringá, 2003.

HAO, Karen. AI is sending people to jail - and getting it wrong. Technologyreview.com, 2019. Disponível em: https://bit.ly/3zrDAOt. Acesso em: 11 dez. 2019.

KURZWEIL, Ray. A era das máquinas espirituais. São Paulo: Aleph, 2013.

LÉVY, Pierre. Cibercultura. São Paulo: Editora 34, 1999.

McCULLOCH, Warren; PITTS, Walter (1943). A logical calculus of the ideas immanent in nervous activity. The bulletin of mathematical biophysics, 5(4):115-133, 1943. Disponível em: http://dx. doi.org/10.1007/BF02478259 Acesso em: 30 nov. 2021. 
MELO, Jeferson. Judiciário ganha agilidade com uso de inteligência artificial. Cjn.jus.br, 2019. Disponível em: https://bit.ly/3qM1H9a. Acesso em: 11 dez. 2019.

NEGRI, Sergio Marcos Carvalho Avila. Robôs como pessoas: a personalidade eletrônica na Robótica e na inteligência artificial. In: Pensar, Fortaleza, v. 25, n. 3, p. 1-14, jul./set. 2020. Disponível em: https://bit.ly/3JGdnAm. Acesso em: 30 nov. 2021.

NORVIG, Peter; RUSSEL, Stuart. Inteligência artificial. São Paulo: Elsevier, 2004.

PROCTOR Helen S.; CARDER Gemma, CORNISH Amelia R. Searching for Animal Sentience: A Systematic Review of the Scientific Literature. Animals (Basel). 2013 Sep 4;3(3):882-906. DOI: 10.3390/ani3030882. PMID: 26479539; PMCID: PMC4494450. Disponível em: https://bit.ly/32Pnp1B. Acesso em: 20 out. 2021.

RASO, Filippo et Al. Artificial Intelligence \& Human Rights: Opportunities \& Risks. Berkman Klein Center, 25 de Setembro de 2018. Disponível em: https://bit.ly/3zo6xuG. Acesso em: 10 nov. 2021.

OLIVEIRA JÚNIOR, José Alcebíades de. Teoria Jurídica e novos direitos. Rio de janeiro: Lúmen Juris, 2000.

PASQUALE, Frank. New laws of robotics: defending human expertise in the age of AI. Cambridge, Massachusetts: The Belknap Press Of Harvard University Press, 2020.

PEREZ, Sarah. Microsoft silences its new A.I bot Tay, after Twitter users teach it racism [Updated]. Techcrunch.com, 2016. Disponível em: https://tcrn.ch/3zsQewx Acesso em: 11 dez. 2019.

SALVO, Rodrigo de Vasconcelos. Juízes artificiais: Aplicação da Inteligência Artificial no julgamento de processos. (Projeto de Pesquisa). Universidade Federal de Uberlândia. 2020. Disponível em: https://bit.ly/3FUjcYI. Acesso em: 30 nov. 2021.

SILFWER, Jerry. Meet Replika my AI chatbot friend, 2020. Disponível em: https://bit.ly/3zobgwy. Acesso em: 11 dez. 2019.

SOUZA, Ramos de. Manifesto propõe regras para que machine learning não fira direitos humanos. Disponível em: https://bit.ly/3G0B0Bx. Acesso em: 11 dez. 2019. 
SZANIAWSKI, Elimar. Direitos de personalidade e sua tutela. São Paulo: RT, 2002.

TURNER, Jacob. Robot Rules: Regulating Artificial Intelligence. Nova York: Palgrave Macmillan, 2019.

UNIÃO EUROPEIA. Resolução do Parlamento Europeu, de 16 de fevereiro de 2017. Com recomendações à Comissão Direito Civil sobre Robótica. Bruxelas: Parlamento Europeu, 2017. Disponível em: https://bit.ly/3t1R3LI. Acesso em: 28 out. 2021.

UNIÃO EUROPEIA. Proposal for a Regulation of the European Parliament and the Council Laying Down Harmonized Rules on Artificial Intelligence (Artificial Intelligence Act) and Amending Certain Union Legislative Acts (COM/2021/206). Bruxelas: Comissão Europeia, 2021.

VINCENT, James. Watch Jordan Peele use AI to make Barack Obama deliver a PSA about fake News. Theverge, 2018. Disponível em: https://bit.ly/3qQVExw. Acesso em: 11 dez. 2019.

WARNER, Bernhard. Fighting Deepfakes Gets Real. Fortune.com, 2019. Disponível em: https:// bit.ly/3EWlh50. Acesso em: 11 dez. 2019.

WERNECK, Vivi. O que é Ray Tracing? 2019. Disponível em: https://bit.ly/3zo7H9q. Acesso em: 7 dez. 2020. 